\title{
MODERN OPPORTUNITIES OF RADIONUCLIDE METHODS FOR DIAGNOSIS OF INFLAMMATORY PROCESSES IN THE MYOCARDIUM
}

\author{
Sazonova S.I., llyushenkova Yu.N., Lishmanov Yu.B.
}

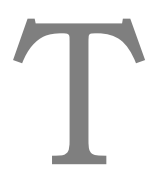

he review is devoted to the radionuclide diagnostics of inflammatory processes in the myocardium. The work briefly describes the main radiopharmaceuticals proposed for visualization of inflammation in cardiology, compares their scintigraphic characteristics, parameters of sensitivity and specificity. The authors discuss unsolved problems, as well as the prospects of nuclear medicine in terms of diagnosing inflammatory diseases. Literature was searched using electronic bibliographic databases, such as Medline, PubMed, E-library.

Keywords: myocarditis, cardiac inflammation, scintigraphy, radiopharmaceuticals.

Corresponding author: Sazonova S.I., e-mail: sazonova_si@mail.ru

For citation: Sazonova S.I., Myushenkova Yu.N., Lishmanov Yu.B. Modern opportunities of radionuclide methods for diagnosis of inflammatory processes in the myocardium. REJR. 2017; 7 (2):142-150. DOI:10.21569/2222-7415-2017-7-2-142-150.

Received: 05.04.2017

Accepted: 15.05.2017

\section{СОВРЕМЕННЫЕ ВОЗМОЖНОСТИ РААИОНУКАИАНЫХ МЕТОАОВ ИССАЕАОВАНИЯ В АИАГНОСТИКЕ ВОСПАЛИТЕАЬНЫХ ПРОЦЕССОВ В MUOKAPAE}

\author{
Сазонова С.И., Ильюшенкова Ю.Н., Аишманов Ю.Б.
}

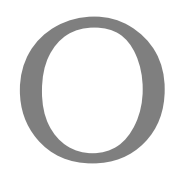

бзор митературы посвящен вопросам радионуклидной диагностики воспаАительных процессов в миокарде. В работе кратко охарактеризованы основные радиофармпрепараты, предложенные для визуализации воспаления в кардиологии, сравниваются их сцинтиграфические характеристики, параметры чувствительности и специфичности. Авторами рассматриваются нерешенные вопросы, а также перспективы ядерной медицины в плане диагностики воспалительных заболеваний. Поиск митературы был выполнен с помощью электронных библиографических баз данных таких как Medline, PubMed, E-library.

К^ючевые слова: миокардит, кардиальное воспаление, сцинтиграфия, радиофармпрепараты.

Контактный автор: Sazonova S.I., e-mail: sazonova_si@mail.ru

Для uитирования: Sazonova S.I., Ilyushenkova Yu.N., Lishmanov Yu.B. Modern opportunities of radionuclide methods for diagnosis of inflammatory processes in the myocardium. REJR. 2017; 7 (2):142-150. DOI:10.21569/2222-7415-2017-7-2-142-150.

Научно-

исследовательский институт кардиологии. ФГБНУ «Томский национальный исследовательский медицинский центр Российской академии наук".

г. Томск, Россия. 
yocarditis is an inflammatory lesion of the heart muscle, which can be caused by infections, including viral nature, as well as autoimmune processes and the effect of cardiotoxic agents [1]. The diagnosis of myocarditis is one of the most difficult problems in cardiology. This is due to the objective and subjective difficulties in verifying the diagnosis in these diseases [2, 3]. The clinical symptomatology of myocarditis is very similar to other forms of noncoronary heart disease, and the currently accepted laboratory-instrumental criteria for its diagnosis are low-specific $[1,2,3]$. It is considered that finally the diagnosis of myocarditis can be confirmed only by endomyocardial biopsy [1, 2, 3, 4]. However, these data are depend on the site of the puncture, and therefore only the positive results of the EMB are really true. Taking into account the invasiveness of the procedure, endomyocardial biopsy is usually performed only in cases of unfavorable course of the disease or inefficiency of the therapy [5,6]. In connection with this, the risk of untimely recognition of myocarditis and the appointment of ineffective treatment is great, which can lead to a chronic process with the likely development of cardiosclerosis, persistent of rhythm disturbances and chronic heart failure.

Nowadays, timely and high-quality diagnosis of inflammatory heart diseases is impossible without the use of radiological methods that are highly informative, allowing to assess the anatomical and pathophysiological changes in the affected organs and tissues. Among the commonly used methods of cardiac visualization are ultrasound scanning and magnetic resonance imaging (MRI).

Echocardiography (EchoCG) is recommended for all patients with suspicion of myocarditis and is directed, first of all, to the exclusion of other morphological and functional changes in the heart and its valves. There are no specific echocardiographic signs for myocarditis.

It is known that when performing echocardiography in patients with myocarditis, a picture of dilated cardiomyopathy may be observed [7]. But most often in patients with a low-symptom or asymptomatic course of myocarditis, changes may be absent or it is possible to determine a slight increase in the end-systolic and end-diastolic volumes of the left ventricle.

The MRI allows visualizing the edema of the interstitial space, which is proper for the inflammatory process, as well as the zones of local compaction, thinning and hypokinesis of the myocardium which are proper for fibrosis $[8,9,10]$. Experts from the Group on CMR Diagnosis of Myocarditis in 2009 developed criteria for MR diagnosis of myocarditis ("Lake Louise" criteria), the accuracy of which is $80 \%$ for the detection of acute inflammation of the myocardium (Friedrich
MG et al, 2009;) [ 9]. Unfortunately, when MRI is performed later than 2 weeks from the onset of the disease, the sensitivity of the study is significantly reduced [9].

In recent years, the methods of gamma scintigraphy, which can show the physiological and biochemical processes occurring in the organs, have been proposed for the diagnosis of myocardial inflammation [11, 12]. This is achieved through the use of radiopharmaceuticals (RPH) which are tropic to certain molecular structures, and also are able to be metabolized in certain organ [11].

The methodology of radionuclide diagnostics of heart inflammation is differing from that used for inflammatory diseases of other organs.

This is due to physiological, anatomical features of the heart, as well as pathophysiological differences of cardiac inflammation $[1,13]$.

For heart inflammation it is impossible to use "traditional" non-specific RPH (except 67Ga), which accumulate in the pathological focus due to increased vascular permeability and increased blood flow [14], since the blood filling of the damaged tissue is significantly lower than blood volume of the heart ventricles.

As it is known, all stages and forms of myocarditis are characterized by the presence of lymphocytic infiltration and foci of necrosis in the myocardium, as well as the granulation and fibrosis in chronic course of the disease [1].

In this regard, in nuclear cardiology are used RPH that fix in the area of cardiomyocytes damage mainly due to the release of their intracellular elements into the interstitial space. Such RPH include:

1. $67 \mathrm{Ga}$-citrate;

2. Radiopharmaceuticals for evaluation of myocardial perfusion $\quad\left({ }^{99} \mathrm{mTc}-\mathrm{MIBI}, \quad{ }^{99} \mathrm{mTc}-\right.$ tetrofosmin, 201Tl);

3. Radiopharmaceuticals for diagnosis of myocardial damage (labeled with 111In antimyosin antibodies, ${ }^{99} \mathrm{mTc}$-pyrophosphate).

Lymphocytic myocardial infiltration in myocarditis can be visualized with "traditional" specific $\mathrm{RPH}$, which accumulate in the inflammatory foci due to exudation and emigration of immunocompetent cells. The specific group of $\mathrm{RPH}$ includes:

1. Leucocytes labeled with 111In-oxine or 99mTc-HMPAO;

2. Fragments of monoclonal antibodies to granulocytes labeled with $99 \mathrm{mTc}$.

In recent years, positron emission tomography with 18 fluorodeoxyglucose (FDG) combined with computed tomography (PET/CT) has been increasingly used to diagnose myocardial inflammation. This RPH accumulates in the inflammatory lesion due to increased glucose metabolism of 
activated macrophages present in the inflammatory $[15,16]$.

Next the capabilities of the above RPH in clinical practice and the methodology of radionuclide diagnostics of the heart inflammation will be considered.

The first radiopharmaceutical proposed for the diagnosis of inflammation in the myocardium was $67 \mathrm{Ga}$-citrate $[17,18]$. The possibility of using this indicator in cardiology was shown by Reeves W.C. With et al. [19] in 1981 on the model of myocarditis in rabbits.

The accumulation of $67 \mathrm{Ga}$ in the inflamed myocardium is explained by chemical properties of the gallium, which are similar to ferric iron (Fe3 + ). The $67 \mathrm{Ga}$ uptake occurs as a result of its passive transmembrane diffusion and the formation of $67 \mathrm{Ga}$ complex with proteins that have an affinity for iron $[17,18]$.

To date $67 \mathrm{Ga}$ in cardiology is rarely used, because it slowly accumulates in the inflammatory focus, has a non-optimal radiological characteristics, a relatively long half-life, and its sensitivity is inferior to modern radiopharmaceuticals [19, 20].

Over the past 10 years, only a few manuscripts concerning the visualization of myocardial inflammation with $67 \mathrm{Ga}$ have been published. In particular, Hung M.Y., Hung M.J., Cheng C.W. in 2007 showed the possibility of differential diagnosis of acute myocarditis and acute myocardial infarction with the use of this RPH [21]. In 2009 Momose $\mathrm{M}$ et al demonstrated the possibility of cardiac sarcoidosis using imaging using SPECT/CT with 67Ga. The authors showed a higher efficiency of hybrid images comparing with isolated use of the SPECT (sensitivity $77 \%$ vs $69 \%$, specificity $79 \%$ vs $54 \%$, accuracy $76 \%$ vs $62 \%$ ) [22]. It should be noted that the presented studies were performed on a small group of patients (less than 15 people).

Radiopharmaceuticals for myocardial perfusion imaging are not specific for inflammation and can be used to obtain additional information, in particular, on the severity of damage or fibrosis in myocarditis.

For this purpose, ${ }^{99} \mathrm{mTc}-\mathrm{MIBI}$ and $201 \mathrm{Tl}$ are used. The intensity of their accumulation in the myocardium depends on the state of coronary blood flow, of the integrity of membranes and the metabolism of cardiomyocytes [11]. Since inflammation and microbial invasion lead to local necrosis in the myocardium, changing of cellular homeostasis and energy metabolism, the myocarditis, as a rule, is accompanied by perfusion defects [23, $24,25,26]$.

Unfortunately, the results of SPECT obtained using ${ }^{99} \mathrm{mTc}-\mathrm{MIBI}$ and $201 \mathrm{Tl}$ are nonspecific and do not allow to differentiate coronary artery disease (CAD) with myocarditis [11]. The only feature of myocarditis is the less pronounced pathological changes on scintigraphic images [24, 25, 26].

However, according to Sun Y. et al. [27] the value of perfusion defects is closely correlated with the clinical and laboratory-instrumental manifestations of inflammatory processes in the myocardium. Similar data were obtained by De Winter et al in 2005 [28]. This indicates the prospects for using perfusion scintigraphy to predict the course of this pathology.

Radionuclide markers for myocardium damage imaging were initially created for the diagnosis of acute myocardial infarction. They are fixed in the area of damage, mainly due to interaction with chemical compounds that are formed and accumulate in the cardiac muscle during necrosis of cardiomyocytes [29]. These same processes accompany the alterative stage of myocardial inflammation [30]. The most widely used among them are 99mTc-pyrophosphate and antimyosin antibodies, labeled with 111 In [31, 32, 33,34].

The possibility of using ${ }^{99} \mathrm{mTc}-$ pyrophosphate for myocardial inflammation imaging was shown in 1978 by Riba A.L. et al. on the model of infective endocarditis of the aortic valve [35]. A little later Matsumori A et al. (1980) performed similar research on the model of viral periomyocarditis [36].

The mechanism of ${ }^{99} \mathrm{mTc}$-pyrophosphate uptake by damaged myocardium has not been fully studied. It is assumed that the accumulation of the tracer in the heart is the result of the formation of granules of crystalline hydroxyapatite (calcium phosphate compound) in the mitochondria of irreversibly damaged cardiomyocytes [29].

Another possible mechanism of $99 \mathrm{mTc}-$ pyrophosphate uptake in the cardiac muscle is the non-specific sorption of $99 \mathrm{mT}$ Tc compounds by denatured macromolecules or enzymes, for example, phosphatases [29]. All these processes accompany other non-coronary heart diseases, for example, cardiomyopathy, and this reduces the specificity of the method in the diagnosis of inflammation [37, 38].

To date, ${ }^{99} \mathrm{mTc}$-pyrophosphate is most frequently used for cardiac amyloidosis visualization $[34,39,40,41]$. In particular, according to the multicenter study performed by Castano A. et al in 2016, the efficiency of the SPECT with ${ }^{99} \mathrm{mTc}$ pyrophosphate in the diagnosis of this pathology was: sensitivity - 91\%, specificity - 92\%. It was found that the value of the heart/contralateral side coefficient of more than 1.6 is a predictor of poor prognosis of survival in patients with cardiac amyloidosis [40].

In modern clinical practice 99mTcpyrophosphate for the diagnose of myocardial inflammation is used rarely and in the literature of 
the last decade there are only a few publications devoted to this problem. This is probably due to the fact that the results of scintigraphy cannot affect the choice of myocarditis treatment, in which the leading role is assigned to the morphological and molecular-genetic studies of endomyocardial samples [1, 2, 3].

At the same time, according to our data, the sensitivity, specificity and diagnostic accuracy of the SPECT with ${ }^{99} \mathrm{mTc}$-pyrophosphate combined with myocardial perfusion scintigraphy are rather high $(80 \%, 83 \%, 82 \%$, respectively) in diagnostics of latent chronic myocarditis [40]. In this regard, for our opinion, scintigraphy with ${ }^{99} \mathrm{mTc}$ pyrophosphate can be used as an additional method for selecting patients with suspected myocarditis for endomyocardial biopsy.

The background for the creation of ${ }^{111} \mathrm{In}$ labeled antimyosin antibodies ( $\left.{ }^{111} \mathrm{In}-\mathrm{AMM}\right)$ were the low ability of the latter to cross-link with a similar skeletal muscle protein, and the fact that "cardiac" myosin enters the interstitial space and becomes available for the "antigen-antibody" reaction only in damaged cardiomyocytes [29, 43].

Scintigraphic diagnosis of myocarditis with ${ }^{111}$ In-AMM ("Myoscint"), has high sensitivity values (83\%), but low specificity $(53 \%)$ [29, 43]. This situation is due to the ability of this RPH to accumulate in the cardiac muscle in other noncoronogenic myocardial diseases accompanied by an alteration, for example, in the case of cardiomyopathy $[31,44]$.

Intensity of myocardial accumulation of ${ }^{111}$ In-AMM has, according to Martin R. et al. [44], the inverse correlation dependence with the duration of myocarditis. This is explained by the fact that in the acute stage of the disease the damage of cardiomyocytes is expressed to the greatest extent. Further, the level of alteration decreases, causing a decrease in accumulation of the indicator [44].

Nowadays, despite the high diagnostic efficacy the ${ }^{111}$ In-AMM practically are not used, since ${ }^{111}$ In has a non-optimal radiological characteristics, a relatively long half-life, and inferior to modern radiopharmaceuticals sensitivity [11].

The possibility of using labeled leukocytes for the diagnosis of myocardial inflammation was first shown by Weiss E.S. in 1977 [45] on the example of the accumulation of ${ }^{111}$ In-leukocytes in the area of myocardial infarction.

Later Riba A.L. et al. in 1978 [46] in this way tried to visualize the experimental infective endocarditis of the aortic valve, but get negative results.

Single clinical studies of ${ }^{111}$ In-leukocytes were performed in the late 80's and early 90's. So, Oates E in 1988 [47] and Cerqueira M.D. in 1989 [48] diagnosed abscesses of the aortic valve in patients with infective endocarditis. Barst U. et al. in
1993 [49] get a positive correlation between the activity of the disease and the intensity of accumulation of $\mathrm{s}$ labeled with ${ }^{99} \mathrm{mTc}$ or ${ }^{111} \mathrm{In}$ leukocytes.

In clinical practice, for leukocytes labelling the $99 \mathrm{~m}$ Tc preparations are preferable, since they have optimal radiation characteristics. The method of "labeled leukocytes" is widely used to detect inflammatory foci of any localization, except the pathology of the spleen $[50,51]$.

In nuclear cardiology, leukocytes labeled with ${ }^{99} \mathrm{mTc}$-HMPAO are used primarily for visualization of infective endocarditis [52] and infectiousinflammatory complications after implantation of pacemakers [53]. Publications on the diagnosis of myocarditis using this method are single.

Thus, M.V. Deryugin and S.A. Boytsov [54] in 2005 compared the results of complex radioisotope diagnosis of myocarditis, including scintigraphy with leucocytes labeled with ${ }^{99} \mathrm{mTc}$ TMPAO, and evaluation of myocardial perfusion at rest with data from instrumental and clinical studies. They showed high specificity and sensitivity of the radionuclide method. At the same time, the authors noted "some discrepancy" between the results of scintigraphy and endomyocardial biopsy $[54,55]$.

We also studied the efficacy of SPECT with ${ }^{99} \mathrm{mTc}$-HMPAO-leukocytes in the diagnosis of chronic myocarditis and compared scintigraphy with histological examination of the myocardium. Based on the results of this work, the sensitivity, specificity and diagnostic accuracy of the method were $62 \%, 92 \%, 85 \%$, respectively $[12,56,57,58$, 59].

Despite the rather high diagnostic value, the method of "labeled leukocytes" has a number of significant drawbacks, coupled with technical difficulties in its implementation. In this regard, since the introduction of scintigraphy with "labeled leukocytes" into clinical practice, the researchers began developing RPH for the labeling of leukocytes in vivo. Advances in the development of modern biochemical and radiopharmaceutical technologies have made it possible to solve this problem, and radionuclide indicators which are able to bind specifically with the receptors of immunocompetent cells migrating to the inflammatory region, have been synthesized. Thus, at present, the production of diagnostic kits "LeukoS$\operatorname{can}{ }^{\circledR}$ " for the technetium-99m generators, which are fragments of antibodies to granulocytes (Fab '), has been established. The mechanism of accumulation of $99 \mathrm{mTc}-\mathrm{Fab}$ in the pathological focus is mainly due to their interaction with surface receptors of granulocytes and non-specific diffusion into the lesion due to increased vascular permeability [60].

This indicator is widely used for imaging the inflammation of soft tissues [61, 62, 63, 64]. 
In nuclear cardiology, an attempt was previously made to use LeukoScan ${ }^{\circledR}$ for the diagnosis of endocarditis $[65,66]$. So, the scintigraphic studies performed by Grats M.D. et al. in 2000 [65], showed a high diagnostic accuracy of the method for visualization of inflammation in the endocardium. However, in the literature of the last decade, works devoted to this problem are presented only by single descriptions of clinical cases [67].

There are also separate publications in which the possibility of using immunoscintigraphy for the diagnosis of myocarditis has been presented [68, 69]. These studies were performed on a small group of patients, and scintigrams were not combined with the anatomical contours of the heart.

Particular attention in the framework deserves the positron emission computed tomography (PET) with 18F-fluorodeoxyglucose (18FDG), which is one of the most sensitive methods of visualization of inflammatory foci [70, 71]. This method has several advantages over SPECT including reducing the duration of the study a higher spatial resolution, the possibility of performing quantitative analysis and providing information on the state of the organs and tissues [70, 71]. The method is based on visualization of the accumulation of the 18FDG in glycolytically active cells, including neutrophils, monocytes and macrophages. In addition, microvascular damage, damage to cardiomyocytes, and changes in fatty acid metabolism are the causes of increased glucose metabolism in the inflamed myocardium [72, 73].

To date, this method has been successfully used to diagnose sarcoidosis, amyloidosis, and cardiovascular implantable electronic device infection [72, 73, 74].

Publications concerning the possibility of myocarditis imaging using PET with 18FDG are limited.

So, a clinical example, when an acute inflammatory myocarditis was detected using hybrid 18FDG/MRI in Epstein Barr virus infection, was presented. In patient with LV systolic dysfunction, pericardial effusion according to ECHO-CG data, and heterogeneously increased accumulation of $18 F D G$ in LV myocardium were found. The presence of active myocarditis was confirmed by histological examination of fragments of endomyocardium [75].

Tung $\mathrm{R}$ et al, when using PET with $18 \mathrm{FDG}$, visualized foci of increased accumulation of $\mathrm{RPH}$ in 50 out of 103 examined patients with idiopathic cardiomyopathy and ventricular arrhythmias. Among them, endomyocardial biopsy was performed in 10 patients, according to which myocarditis was verified in 9 (90\%) patients [76].

In 2016, Nensa F et al compared MRI data and 18FDG-PET studies in 65 patients with suspected myocarditis [77]. The authors found good consistency between the results of these methods.
The sensitivity, specificity and diagnostic accuracy of PET in relation to MRI were $74 \%$ and $97 \%$, respectively.

In the Ozawa K et al 2013 study, the consistency of 18FDG-PET and endomyocardial biopsy results was demonstrated in terms of detection of the active inflammatory process of the posterior wall of the left ventricle in patients with clinical signs of active acute myocarditis [78]. The authors also found that the method is most informative within 14 days from the onset of the manifestation of the disease.

Discussing the use of 18FDG-PET for the diagnosis of myocardial inflammation, it should be noted that the heart normally has a high glucose metabolism and for a qualitative visualization of the cardiac inflammation, a preliminary preparation of the patient is required, aimed at reducing the physiological accumulation of 18FDG in the myocardium. This can be achieved by switching cardiomyocytes to the metabolism of free fatty acids (using fasting, a high-lipid diet), or by blocking the transport of glucose to cardiomyocytes (use of calcium channel blockers). Given this feature, the diagnosis of inflammation requires the use of special protocols and patient compliance with a special low-carbohydrate diet $[73,78]$.

Despite the fact that PET with 18 FDG has high sensitivity in the diagnosis of inflammation, a number of authors have noted a rather low specificity of the method $[79,80,81]$. In a study of Rouzet F. et al. a comparison of PET-CT with $18 F D G$ and SPECT-CT with ${ }^{99} \mathrm{mTc}-\mathrm{HMPAO}-$ labeled autoleukocytes for diagnoses of endocarditis was performed, and it was shown that the scintigraphy study had a significantly higher diagnostic efficiency compared to PET [82 ].

To solve this problem, the use of in vitro labeled 18FDG autologous leukocytes was suggested. This technique is successfully used to visualize the inflammation of various localizations and has high specificity - from $85 \%$ to $96 \%$ according to different authors [82, 83, 84]. At the same time, labeling of leukocytes in vitro, as was mentioned above, involves certain difficulties [50, 51].

To date, the search and synthesis of new radiopharmaceuticals for the diagnosis of myocarditis are continued, but publications concerning this subject are limited.

The research group of Lee S.P. et al suggested that a new ${ }^{68} \mathrm{Ga}-\mathrm{NOTA}-\mathrm{MSA}$ PET tracer which has the affinity with macrophage and originally designed for visualization of the lymph nodes, could be used to detect inflammatory infiltrates in the myocardium [85]. In this study the authors used a model of myocarditis in mice, while the presence of inflammation was verified at the end of the PET scan by histological, immunohistochemical and immunofluorocene methods. 
Images of the mice hearts with and without myocarditis were compared, and the reliability of differences in the intensity of accumulation of $68 \mathrm{Ga}$ NOTA-MSA in the myocardium was found to be 0.32 (0.31 0.33 SUV) vs 1.02 (0.86 1.06 SUV) $\mathrm{p}=0.010$. These results demonstrated the prospects of using this PET-tracer for the visualization of inflammatory infiltrates in the myocardium.

Benali $\mathrm{K}$ et al in 2014 used a new radiopharmaceutical ${ }^{99} \mathrm{mTc}$-annexin A5-128, which is a derivative of human annexin and has an affinity for the apoptosis marker - phosphatidylserine, to detect experimental autoimmune myocarditis [86]. The results showed high diagnostic sensitivity of new RPH.

Researchers Taki J et al [87] suggested that a PET with $11 \mathrm{C}$-methionine, which is successfully used in oncology [88], can be used to diagnose cardiac inflammation and, in addition, can accumulate in areas of the infarcted myocardium [89]. The likely mechanism for the accumulation of this radiopharmaceutical in necrotic areas of the myocardium is the affinity to the initial stages of reparation and angiogenesis [87], which also occurs with inflammatory damage.

Later Maya Y et al [90] sequentially intravenously injected $11 \mathrm{C}$-methionine and $18 \mathrm{FDG}$ to rats with an autoimmune myocarditis model and compared the resulting images. It was shown that the arears of increased $\mathrm{f} 11 \mathrm{C}$-methionine and 18FDG uptake in the heart coincide. The authors concluded that $11 \mathrm{C}$-methionine is a promising marker of myocardial inflammation.

Thus, the methods of scintigraphic diagnostics of myocarditis presented in this review have variable diagnostic efficiency, which makes

\section{References:}

1.Shapchenko A.V., Arabidze G.G., Tebloev K.I., Muslimova O.V., Borisov V.G. Myocarditis: classification, pathogenesis, clinic, diagnostics, treatment. Therapeutist. 2011; 6: 50-65 (in Russian).

2.Blagova O.V., Nedostup A.V. Modern masks of myocarditis (from clinical signs to diagnosis). Russian journal of cardiology. 2014; 5(109): 13-22 (in Russian).

3.Moiseeva O.M., Mitrofanova L.B., Pahomov A.V., Mitrofanov N.A. Basic principles of diagnostics of inflammatory diseases of the myocardium. Translational medicine. 2012; 4: 63-71(in Russian).

4.Moiseeva O.M. Myocarditis: basic principles of diagnosis and treatment. Cardiology: news, opinion, training. 2016; 1(8): 48 59(in Russian).

5.Shostak N.A., Klimenko A.A., Shemenkova V.S., Loginova T.K. Non-rheumatic myocarditis. Clinicist. 2015; 3(9): 46-51(in Russian).

6.Sławek S., Araszkiewicz A., Gaczkowska A., Koszarska J., Celinski D., Grygier M., et al. Endomyocardial biopsy via the their interpretation necessary only in combination with the results of general clinical examination. Despite the large number of potential radiotracers for visualization of cardiac inflammation, studies devoted to this problem are limited. This is probably due to the relatively low resolution of radionuclide techniques and the inability to visualize small infiltrates. At the same time, this lack of scintigraphy is largely overcome by using hybrid techniques (SPECT/CT, PET/CT), which allows to accurately determine the location of pathological foci and to obtain additional radialogical criteria for the inflammatory process. Many researchers emphasize that the best prospects within the discussed problem has the PET-MRI, which, however, is not yet widely used in clinical practice.

It should also be emphasized that scintigraphy as an isolated method of examination can not affect the tactics of myocarditis treatment, which includes mainly correction of heart failure or heart rhythm disturbances. Specific therapy is based on the use of glucocorticoids in a limited contingent of patients $[1,3,4]$ and antiviral therapy prescribed in case of a persistence of viral infection in endomiocardial specimens obtained from endomyocardial biopsy [1, 3, 4]. However, in our opinion, radioisotope methods of investigation can be used to obtain additional reasons for performing an invasive diagnostic procedure, as well as for monitoring the disease. In addition, rapid progress in the development of molecular biology and radiopharmaceuticals contributes to the creation of newer and more advanced RPHs and leaves no doubt that the problem of scintigraphic diagnosis of myocardial inflammation can be solved soon.

femoral access - still safe and valuable diagnostic tool. BMC Cardiovascular Disorders. 2016; 16(1): 222. DOI: 10.1186/s12872-016-0406-0.

7.Lieback E., Hardouin I., Meyer R., Bellach J., Hetzer R. Clinical Value of Echocardiographic Tissue Characterization in the Diagnosis of Myocarditis. European heart journal. 1996; 17(1): 13542.

8.Safiullina A.A., Sharia M.A., Narusov O.Iu., Alaeva E.N., Tereshchenko S.N. Diagnostic capabilities of cardiac magnetic resonance imaging in patients with inflammatory cardiomyopathy: comparison of its results with endomyocardial biopsy data and clinical picture. Terapevticheskī arkhiv. 2013; 85(4):22-8 (in Russian).

9.Friedrich M.G., Sechtem U., Schulz-Menger J., Holmvang G., Alakija P., Cooper L. T., et al. Cardiovascular magnetic resonance in myocarditis: A JACC White Paper. Journal of the American College of Cardiology. 2009; 28; 53(17): 1475-1487. DOI: 10.1016/j.jacc.2009.02.007.

10.Radunski U.K., Lund G.K., Säring D., Bohnen S., Stehning C., 


\section{RUSSIAN ELECTRONIC JOURNAL OF RADIOLOGY}

Schnackenburg B., et al. T1 and T2 mapping cardiovascular magnetic resonance imaging techniques reveal unapparent myocardial injury in patients with myocarditis. Clinical research in cardiology. 2017; 106(1): 10-17. DOI: 10.1007/s00392-0161018-5.

11.Lishmanov Yu.B., Chernov V.I. National guidance for radionuclide diagnosis. Tomsk, STT, 2010. 418 p (in Russian).

12.Lishmanov Yu.B., Sazonova S.I., Chernov V.I., Knyazeva E.K., Evtushenko A.V. The scintigraphic diagnosis of inflammatory heart disease. Medical radiology and radiation safety. 2004; 2(49): 59-66 (in Russian).

13.Osipov A.I. Diastolic function of the heart. Siberian medical journal (Irkutsk). 2002; 6(35): 22-26 (in Russian).

14.Sazonova S.I., Lishmanov Yu.B. Radiopharmaceuticals for scintigraphic imaging of inflammatory foci. Medical radiology and radiation safety. 2007; 4: 73-82 (in Russian).

15.Erba P.A., Sollini M., Lazzeri E., Mariani G. FDG-PET in cardiac infections. Seminars in nuclear medicine. 2013; 43(5):37795. DOI: 10.1053/j.semnuclmed.2013.04.003

16.Byshevsky A.Sh., Tersenov O.A. Biochemistry. Ekaterinburg, "Ural worker", 1994. 92 p (in Russian).

17.Lavender J.P., Lowe J., Barker J.R., Burn J.I., Chaudhri M.A. Gallium 67 citrate scanning in neoplastic and inflammatory lesions. The British journal of radiology. 1971; 44(521):361-6. DOI:10.1259/0007-1285-44-521-361.

18.Palestro C.J. The Current Role of Gallium Imaging in Infection. Seminars in nuclear medicine. 1994; 24(2):128-41.

19.Reeves W.C., Jackson G.L., Flickinger F.W., Kwee H.G., Schwiter E.J., Werner J. et al. Radionuclide Imaging of Experimental Myocarditis. Circulation. 1981; 63(3):640-4.

20.Yilmaz K., Klingel R., Kandolf A., Sechtem U. Imaging in Inflammatory Heart Disease: from the Past to Current Clinical Practice. Hellenic journal of cardiology. 2009; 50(6):449-60.

21.Hung M.Y., Hung M.J., Cheng C.W. Use of Gallium 67 Scintigraphy to Differentiate Acute Myocarditis from Acute Myocardial Infarction. Texas Heart Institute journal. 2007; 34(3):305-9. 22.Momose M., Kadoya M., Koshikawa M., Matsushita T., Yamada A. Usefulness of 67Ga SPECT and integrated low-dose CT scanning (SPECT/CT) in the diagnosis of cardiac sarcoidosis. Annals of nuclear medicine. 2007;21(10):545-51. DOI: 10.1007/s12149-007-0064-5.

23.Javadi H., Jallalat S., Pourbehi G., Semnani S., Mogharrabi M., Nabipour I., et al. The Role of Gated Myocardial Perfusion Scintigraphy (GMPS) in Myocarditis: a Case Report and Review of the Literature. Nuclear medicine review. Central \& Eastern Europe. 2011; 14(2):112-5.

24.Sarda L., Colin P., Boccara F., Daou D., Lebtahi R., Faraggi M., et al. Myocarditis in Patients with Clinical Presentation of Myocardial Infarction and Normal Coronary Angiograms. Journal of the American College of Cardiology. 2001; 37(3):786-92.

25.Kataoka S., Momose M., Fukushima K., Serizawa N., Suzuki A., Kondo C., et al. Regional Myocardial Damage and Active Inflammation in Patients with Cardiac Sarcoidosis Detected by Non-invasive Multi-modal Imaging. Annals of nuclear medicine. 2017; 31(2):135-143.

26.Pagnanelli R.A., Basso D.A. Myocardial perfusion imaging with 201Tl. Journal of nuclear medicine technology. 2010; 38(1):1-3. DOI: 10.2967/jnmt.109.068593.

27.Sun Y., Ma P., Bax J.J., Blom N., Yu Y., Wang Y., et al. 99mTc-MIBI myocardial perfusion imaging in myocarditis. Nu- clear medicine communications. 2003; 24(7):779-83. DOI: 10.1097/01.mnm.0000080254.50447.5a.

28.De Winter O., Velghe A., Van de Veire N., De Bondt P., De Buyzere M., Van De Wiele C., et al. Incremental prognostic value of combined perfusion and function assessment during myocardial gated SPECT in patients aged 75 years or older. Journal of nuclear cardiology. - 2005; 12(6):662-70. DOI: 10.1016/j.nuclcard.2005.08.002.

29. Wynne J., Holman L.B., Lesch M. Myocardial scintigraphy by infarct-avid radiotracers. Principles of cardiovascular nuclear medicine. New York: Grune and Stratton, 1978. 230 p.

30. Chernukh A. M. Inflammation. Moscow, Medicine, 1979. 488 p. (in Russian).

31.Margari Z.J., Anastasiou-Nana M.I., Terrovitis J., Toumanidis S., Agapitos E.V., Lekakis J.P., et al. Indium-111 Monoclonal Antimyosin Cardiac Scintigraphy in Suspected Acute Myocarditis: Evolution and Diagnostic Impact. International journal of cardiology. 2003; 90(2-3):239-45.

32.Martin ME, Moya-Mur JL, Casanova M, Crespo-Diez A, AsinCardiel E, Castro-Beiras JM., et al. Role of Noninvasive Antimyosin Imaging in Infants and Children with Clinically Suspected Myocarditis. Journal of nuclear medicine. 2004; 45(3):429-37.

33.Sazonova S.I., Ilyushenkova Yu.N., Lishmanov Yu.B., Batalov R.E., Sazonov A.E., Larionova L.A., Nesterov E.A., Varlamova N.V., Rogovskaya Yu.V., Shelkounikova T.A., Popov S.V. Assessment of radiological techniques application possibility for non-invasive diagnostics of latent inflammatory processes in myocardium in patients with atrial fibrillation. Annals of Nuclear Medicine. 2016; 30(10):738-748. DOI: 10.1007/s12149-0161120-9.

34.Bokhari S., Morgenstern R., Weinberg R., Kinkhabwala M., Panagiotou D., Castano A., et al. Standardization of 99mTechnetium pyrophosphate imaging methodology to diagnose TTR cardiac amyloidosis. Journal of nuclear cardiology. 2016 Aug 31. DOI: 10.1007/s12350-016-0610-4.

35.Riba A.L., Thakur M.L., Gottschalk A., Andriole V.T., Zaret B.L. Imaging Experimental Infective Endocarditis with Indium111-Labeled Blood Cellular Components. Circulation. 1979; 59(2):336-43.

36.Matsumori A., Kadota K., Kawai C. Technetium-99m Pyrophosphate Uptake in Experimental Viral Perimyocarditis. Sequential Study of Myocardial Uptake and Pathologic Correlates. Circulation. 1980; 61(4):802-7.

37.Tamaki N., Yamada T., Matsumori A., Fujita T., Ohtani H., Watanabe Y. Clinical Trial of 111In-Antimyosin Antibody Imaging: Comparison with 99mTc-Pyrophosphate Imaging. Kaku igaku. 1989; 26(9):1199-205.

38.Onishi T., Kobayashi I., Onishi Y., Kawashima T., Muramoto H., Nakamura H., et al. Evaluating Microvascular Obstruction After Acute Myocardial Infarction Using Cardiac Magnetic Resonance Imaging and 201-Thallium and 99m-Technetium Pyrophosphate Scintigraphy. Circulation journal. 2010; 74(12):263340.

39.Castaño A., Maurer M.S., Bokhari S. Technetium 99m pyrophosphate radioisotope for diagnosis and prognosis of transthyretin cardiac amyloidosis: A call for collaboration. Journal of nuclear cardiology. 2017 Feb 1. DOI: 10.1007/s12350-0170803-5.

40.Castano A., Haq M., Narotsky D.L., Goldsmith J., Weinberg R.L., Morgenstern R., et al. Multicenter study of planar techneti- 


\section{RUSSIAN ELECTRONIC JOURNAL OF RADIOLOGY}

um 99m pyrophosphate cardiac imaging: predicting survival for patients with ATTR cardiac amyloidosis. JAMA Cardiology. 2016; 1(8):880-889. DOI: 10.1001/jamacardio.2016.2839.

41.Papantoniou V., Valsamaki P., Kastritis S., Tsiouris S., Delichas Z., Papantoniou Y., et al. Imaging of Cardiac Amyloidosis by $(99 \mathrm{~m}) \mathrm{Tc}$-PYP Scintigraphy. Hellenic journal of nuclear medicine. 2015 Sep-Dec; 18 Suppl 1:42-50.

42.Sazonova S.I., Lishmanov Iu.B., Batalov R.E., Popov S.V., Il'iushenkova Iu.N., Rogovskaia Iu.B., et al. Capabilities of 99mTc-Pyrphotech Single-photon Emission Computed Tomography in Combination With Myocardial Perfusion Scintigraphy in the Evaluation of Inflammatory Changes in the Heart of Patients with Persistent Atrial Fibrillation. Terapevticheskiu arkhiv. 2014; 12(86): 10-14 (in Russian).

43.Lauer B., Kühl U., Souvatzoglu M., Vosberg H., Schultheiss H.P. Antimyosin Scintigraphy for Diagnosis and Follow-up of Patients with Clinically Suspected Myocarditis. Zeitschrift für Kardiologie. 1998; 87(9):691-8.

44.Rioja Martín M.E., Moya Mur J.L., Casanova M., Castro Beiras J.M., Asin Cardiel E., Diez Jiménez L., et al. Study of active Myocardial Damage in Children with Suspected Myocarditis Using Antimyosin Monoclonal Antibodies (AMMoAb-111In). Revista española de cardiología. 1998; 51 Suppl 1:53-9.

45.Weiss E.S., Ahmed S.A., Thakur M.L., Welch M.J., Coleman R.E., Sobel B.E. Imaging of the Inflammatory Response in Iscemic Canine Myocardium with 111 In-Labeled Leucocytes. American College of Cardiology. 1977; 40(2):195-9.

46.Riba A.L., Thakur M.L., Gottschalk A., Andriole V.T., Zaret B.L. Imaging Experimental Infective Endocarditis with Indium111-Labeled Blood Cellular Components. Circulation. 1979; 59(2):336-43.

47.Oates E., Sarno R.C. Detection of Bacterial Endocarditis with Indium-111 Labeled Leukocytes. Clinical nuclear medicine. 1988; 13(10):691-3.

48.Cerqueira M.D., Jacobson A.F. 111 In-Leucocyte Scintiraphic Detection of Myocardial Abscess in Patient with Endocarditis. Journal of nuclear medicine. 1989; 30(5):703-6.

49.Borst U., Becker W., Maisch B., Börner W., Kochsiek K. Clinical and Prognostic Effect of Positive Granulocyte Scan in Ifective Endocarditis. Clinical nuclear medicine. 1993; 18(1):35-9.

50.de Vries E.F., Roca M., Jamar F., Israel O., Signore A. Guidelines for the labelling of leucocytes with (99m)Tc-HMPAO. Inflammation/Infection Taskgroup of the European Association of Nuclear Medicine. European journal of nuclear medicine and molecular imaging. 2010; 37(4):842-8. DOI: 10.1007/s00259010-1394-4.

51.Roca M., de Vries E.F., Jamar F., Israel O., Signore A. Guidelines for the labelling of leucocytes with (111)In-oxine. Inflammation/Infection Taskgroup of the European Association of Nuclear Medicine. European journal of nuclear medicine and molecular imaging. 2010; 37(4):835-41. DOI: 10.1007/s00259-010-13935.

52.Erba P.A., Conti U., Lazzeri E., Sollini M., Doria R., De Tommasi S.M. Added value of 99mTc-HMPAO-labelled leukocytes SPECT/CT in characterization and management of patients with infectious endocarditis. Journal of nuclear medicine. 2012; 53(8):1235-43. doi: 10.2967/jnumed.111.099424.

53.Erba P.A. Infective endocarditis and cardiovascular implantable electronic device. Radionuclide imaging of infection and inflammation. Verlag Italia: Springer, 2013. 181-203p.
54.Deryugin M.V., Boitsov S.A. Chronic myocarditis. Saint Petersburg, ELBI, 2005. 288 p. (in Russian).

55.Boitsov S.A., Deryugin M.V., Sukhov V.Yu. Clinical data evaluation of $c$ scintigraphy with leukocytes labelled with $99 \mathrm{mTc}$ HMPAO, oligosymptomatic patients with non-rheumatic myocarditis. Kardiologia. 2001; 11(41): 48-52 (in Russian).

56.Sazonova S.I., I'yushenkova Y.N., Batalov R.E., Rogovskaya Y.V., Lishmanov Y.B., Popov S.V. Determination of the efficiency of single-photon emission computed tomography with $99 \mathrm{mTC}$ HMPAO-labelled leukocytes in the diagnosis of myocarditis: Comparison of scintigraphic and histological data. Vestnik rentgenologii i radiologii. 2015; 4: 29-34 (in Russian).

57.Sazonova S.I., Lishmanov Yu.B., Batalov R.E., Popov S.V., Ilyushenkova Yu.N., Rogovskaya Yu.V., et al. Possibility of using SPECT with 99mTc-leukocytes for detection of a latent inflammatory processes in the myocardium in patients with atrial fibrillation. Russian electronic journal of radiology. 2015; 2(5): 12 19 (in Russian).

58.Sazonova S.I., Proskokova I.Iu., Guseva A.M., Konkovskaia Iu.A., Garganeeva A.A., Suslova T.E., et al. Radionuclide methods for diagnostics of non-rheumatic myocarditis and postmyocarditic cardiosclerosis. Klinicheskaia meditsina. 2011; 2; 32-35 (in Russian).

59.Sazonova S.I., Lishmanov Yu.B., Proskokova I.Yu., Gusakova A.M., Ilyushenkova Yu.N. The use of gamma-scintigraphy in the complex diagnosis of myocarditis and cardiosclerosis postmyocardial. Radiology - practice. 2013; 3; 24-33 (in Russian).

60.Becker W, Palestro CJ, Winship J, Feld T, Pinsky CM, Wolf $F$., et al. Rapid Imaging of Infections with a Monoclonal Antibody Fragment (LeukoScan). Clinical orthopaedics and related research. 1996; (329):263-72.

61.Albano D., Bosio G., Paghera B., Bertagna F. Comparison between $99 \mathrm{mTC}$-Sulesomab and 18F-FDG PET/CT in a patient with suspected Prosthetic Joint Infection. Clinical nuclear medicine. 2016; 41(6):e298-300. DOI: 10.1097/RLU.0000000000001217.

62.Campennì A., Caruso G., Barresi V., Pino M., Cucinotta M., Baldari S., et al. Gliomas with intratumoral abscess formation: Description of new cases, review of the literature, and the role of (99m)TC-Leukoscan. The Kaohsiung journal of medical sciences. 2015; 31(7):377-83. DOI: 10.1016/j.kjms.2015.03.003.

63.Galletti F., Cammaroto G., Galletti B., Quartuccio N., Di Mauro F., Baldari S. Technetium-99m ( ${ }^{9}{ }^{9} \mathrm{mTc}$ )-labelled sulesomab in the management of malignant external otitis: is there any role? European archives of oto-rhino-laryngology. 2015; 272(6):137782. DOI: 10.1007/s00405-014-2938-1.

64.Quigley A.M., Gnanasegaran G., Buscombe J.R., Hilson A.J. Technetium-99m-labelled sulesomab (LeukoScan) in the evaluation of soft tissue infections. Medical principles and practice. 2008; 17(6):447-52. DOI: 10.1159/000151565.

65.Gratz S., Raddatz D., Hagenah G., Behr T., Béhé M., Becker W. 99mTc-labelled Antigranulocyte Monoclonal Antibody Fab' Fragments Versus Echocardiography in the Diagnosis of Subacute Infective Endocarditis. International Journal of Cardiology. 2000; 75(1):75-84.

66.Gratz S., Beker W. Infection sscintigraphy with 99mTc-

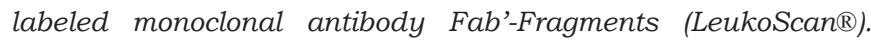
Munchen-Bern-Wien-New York: W. Zuckschwerdt Verlag, 1999. $83 p$.

67.Schiavo R., Ricci A., Pontillo D., Bernardini G., Melacrinis 


\section{RUSSIAN ELECTRONIC JOURNAL OF RADIOLOGY}

F.F., Maccafeo S. Implantable cardioverter-defibrillator lead infection detected by $99 \mathrm{mTC}$-sulesomab single-photon emission computed tomography/computed tomography 'fusion' imaging. Journal of cardiovascular medicine. 2009; 10(11):883-4. DOI: 10.2459/JCM.0b013e32832b35dd.

68.Hubalewska A., Dudek D., Dubiel J., PłaczkiewiczJankowska E., Huszno B., Staszczak A., et al. Screening for Acute Myocarditis - is Scintigraphy with (99m)Tc-AntiGranulocyte BW 250/183 an Answer? Nuclear medicine review. Central \& Eastern Europe. 2004; 7(2):165-9.

69.Ziólkowska L., Kawalec W., Biernatowicz M., Swiatek-Rawa E., Kamińska A., Turska-Kmieć A. The Usefulness of Scintigraphy with (99m)Tc-Anti-Granulocyte Antibody for Diagnosis and Follow-up in Children with Myocarditis. Kardiologia polska. 2012; 70(12):1243-9.

70.Hess S., Hansson S.H., Pedersen K.T., Basu S., HøilundCarlsen P.F. FDG-PET/CT in Infectious and Inflammatory Diseases. PET clinics. 2014; 9(4):497-519, vi-vii. DOI: 10.1016/j.cpet.2014.07.002.

71.Buscombe J. PET Imaging of Inflammation. The quarterly journal of nuclear medicine and molecular imaging. 2014; 58(3):284-9.

72.Miyagawa M., Yokoyama R., Nishiyama Y., Ogimoto A., Higaki J., Mochizuki T. Positron Emission Tomography-Computed Tomography for Imaging of Inflammatory Cardiovascular Diseases. Circulation Journal. 2014; 78(6):1302-10.

73.Juneau D., Erthal F., Alzahrani A., Alenazy A., Nery P.B., Beanlands RS, et al. Systemic and Inflammatory Disorders Involving the Heart: the Role of PET Imaging. The quarterly journal of nuclear medicine and molecular imaging. 2016; 60(4):38396.

74.Orii M., Hirata K., Tanimoto T., Ota S., Shiono Y., Yamano T., et al. Comparison of cardiac MRI and 18F-FDG positron emission tomography manifestations and regional response to corticosteroid therapy in newly diagnosed cardiac sarcoidosis with complet heart block. Heart Rhythm. 2015; 12(12):2477-85. DOI: 10.1016/j.hrthm.2015.06.032.

75.von Olshausen G., Hyafil F., Langwieser N., Laugwitz K.L., Schwaiger M., Ibrahim T. Detection of acute inflammatory myocarditis in Epstein Barr virus infection using hybrid 18F-fluorodeoxyglucose-positron emission tomography/magnetic resonance imaging. Circulation. 2014; 130(11):925-6. DOI: 10.1161/CIRCULATIONAHA.114.011000.

76.Tung R., Bauer B., Schelbert H., Lynch J.P. 3rd, Auerbach M., Gupta $P$., et al. Incidence of abnormal positron emission tomography in patients with unexplained cardiomyopathy and ventricular arrhythmias: The potential role of occult inflammation in arrhythmogenesis. Heart Rhythm. 2015; 12(12):2488-98. DOI: 10.1016/j.hrthm.2015.08.014.

77.Nensa F., Poeppel T.D., Krings P., Schlosser T. Multiparametric assessment of myocarditis using simultaneous positron emission tomography/magnetic resonance imaging. European heart journal. 2014; 35(32):2173. DOI: 10.1093/eurheartj/ehu086.

78.Cussó L., Vaquero J.J, Bacharach S., Desco M. Comparison of methods to reduce myocardial 18F-FDG uptake in mice: calciumchannel blockers versus high-fat diets. PLoS One. 2014; 9(9):e107999. DOI: 10.1371/journal.pone.0107999.
79.Saby L., Laas O., Habib G., Cammilleri S., Mancini J., Tessonnier L., et al. Positron emission tomography/computed tomography for diagnosis of prosthetic valve endocarditis: in creased valvular 18F-fluorodeoxyglucose uptake as a novel major criterion. Journal of the American College of Cardiology. 2013; 61(23):2374-82. DOI: 10.1016/j.jacc.2013.01.092.

80.Kjaer A., Lebech A.M., Eigtved A., Højgaard L. Fever of Unknown Origin: Prospective Comparison of Diagnostic Value of 18F-FDG PET and 111In-Granulocyte Scintigraphy. European journal of nuclear medicine and molecular imaging. 2004; 31(5):622-6.

81.Kouijzer I.J., Vos F.J., Janssen M.J., van Dijk A.P., Oyen W.J., Bleeker-Rovers C.P. The value of 18F-FDG PET/CT in diagnosing infectious endocarditis. European journal of nuclear medicine and molecular imaging. 2013; 40(7):1102-7. DOI: 10.1007/s00259-013-2376-0.

82.Rouzet F., Chequer R., Benali K., Lepage L., Ghodbane W., Duval X., et al. Respective performance of 18F-FDG PET and radiolabeled leukocyte scintigraphy for the diagnosis of prosthetic valve endocarditis. Journal of nuclear medicine. 2014; 55(12):1980-5. DOI: 10.2967/jnumed.114.141895.

83.Rini J.N., Palestro C.J. Imaging of Infection and Inflammation with 18F-FDG-Labeled Leukocytes. The quarterly journal of nuclear medicine and molecular imaging. 2006; 50(2):143-6. Review

84.Aksoy S.Y., Asa S., Ozhan M., Ocak M., Sager M.S., Erkan M.E., et al. FDG and FDG-labelled leucocyte PET/CT in the imaging of prosthetic joint infection. European journal of nuclear medicine and molecular imaging. 2014 Mar;41(3):556-64. DOI: 10.1007/s00259-013-2597-2.

85.Lee S.P., Im H.J., Kang S., Chung S.J., Cho Y.S., Kang H., et al. Noninvasive imaging of myocardial inflammation in myocarditis using 68Ga-tagged mannosylated human serum albumin positron emission tomography. Theranostics. 2017; 7(2):413424. DOI: 10.7150/thno.15712.

86.Benali K., Louedec L., Azzouna R.B., Merceron O., Nassar P., Al Shoukr F., et al. Preclinical validation of $99 \mathrm{mTc}$-annexin A5128 in experimental autoimmune myocarditis and infective endocarditis: comparison with 99mTc-HYNIC-annexin A5. Molecular Imaging. 2014; 13. DOI: 10.2310/7290.2014.00049.

87.Taki J., Wakabayashi H., Inaki A., Imanaka-Yoshida K., Hiroe M., Ogawa K., et al. 14C-Methionine uptake as a potential marker of inflammatory processes aftermyocardial ischemia and reperfusion. Journal of nuclear medicine. 2013; 54(3):431-6. DOI: 10.2967/jnumed.112.112060.

88. Sharma P., Mukherjee A. Newer positron emission tomography radiopharmaceuticals for radiotherapy planning: an overview. Annals of translational medicine. 2016; 4(3):53. DOI: 10.3978/j.issn.2305-5839.2016.01.26.

89.Morooka M., Kubota K., Kadowaki H., Ito K., Okazaki O., Kashida M., et al. 11C-methionine PET of acute myocardial infarction. Journal of nuclear medicine. 2009; 50(8):1283-7. DOI: 10.2967/jnumed.108.061341.

90.Maya Y., Werner R.A., Schütz C., Wakabayashi H., Samnick S., Lapa C., et al. 11C-Methionine PET of Myocardial Inflammation in a Rat Model of Experimental Autoimmune Myocarditis. Journal of nuclear medicine. 2016; 57(12):1985-1990. 